\title{
CORTES DE SAN MATEO-VALENCIA DE 1369-1370
}

\author{
Bibiana Candela Oliver \\ Universidad DE Alicante
}

\begin{abstract}
Resumen: En el presente trabajo nos disponemos a analizar la reunión de las Cortes del reino de Valencia, concretamente la celebrada en 1369-1370 en San Mateo-Valencia, y lo presentamos en tres partes claramente diferenciadas: en primer lugar, comentaremos, de forma general, los estudios realizados entorno a las Cortes, desde las recopilaciones del derecho foral resultado de estas reuniones, los llamados Furs, hasta el análisis de la propia institución y otras surgidas en su seno, como la Diputación General.
\end{abstract}

En segundo término, relacionaremos las diferentes convocatorias de Cortes que tuvieron lugar a lo largo del siglo XIV, y más concretamente bajo el reinado de Pedro, el Ceremonioso, bajo el cual se celebraron las Cortes de San Mateo de 1369. Analizamos los motivos que provocaron estas reuniones, sobre todo el económico, siendo estas Cortes un ejemplo claro de la necesidad real de conseguir donativos destinados, a las empresas bélicas emprendidas por el Ceremonioso, en este caso la guerra contra Castilla. Pero a la vez, el donativo concedido en San Mateo iría dirigido a otro frente abierto en estos momentos: la isla de Cerdeña.

Por último, expondremos todos los detalles de esta convocatoria de Cortes: los asistentes, el donativo, la distribución del mismo, los agravios presentados y todos los aspectos mencionados en las actas referidos a otras reuniones anteriores y que nos proporcionan más datos sobre éstas, todo ello relacionado con el contexto histórico en el que tienen lugar, en este caso, el siglo XIV, conocido por ser un siglo de crisis generalizada, fundamentalmente social y económico.

Palabras clave: Cortes, San Mateo, Reino de Valencia, siglo XIV.

Abstract: This study analysies Cortes meeting of Valencia Kingdom in 1369-1370, in San Mateo-Valencia, and it has tree parts: in the firt time, we'll comment the studies about Cortes and the compilations of law; we'll analyes this institution and others, for exemple the Diputación General. 
In the second time, we'll relate different Cortes sessions during fourteenth century, in the Pedro el Ceremonioso reign, when this Cortes had celebrated in 1369. We'll analyse the reasons of these sessions, above all the economic too, because this Cortes are an exemple of real necessity to get donations to wars, in this case the war against Castilla. But San Mateo donation would finance Cerdeña's front too.

Finally, we'll expose all aspects of this Cortes session: the assistants, the donation's distribute, the grievances and all aspects about others previous sessions. All of this, we'll relate with historic context, in this case the fourteenth century, a century of general crisis, above all social and economical.

Keywords: Cortes, San Mateo, Kingdom of Valence, XIV century.

\section{ESTUDIO DE LAS CORTES MEDIEVALES DEL REINO DE VALENCIA. ESTADO ACTUAL DE LA CUESTIÓN.}

La institución de las Cortes en época medieval, en este caso del reino de Valencia, es un tema aún por estudiar en gran parte, y todavía más por lo que respecta a la publicación de fuentes, lo que nos obliga a recurrir en primer lugar, a los juristas valencianos de los siglos XV al XVII, tales como Belluga, autor del Speculum Principium ${ }^{1}$, Mateu y Sanz, quien publicó en 1654-1656 un estudio sistemático del procedimiento seguido en la convocatoria y celebración de Cortes $^{2}$ y Crespí de Valldaura, miembro participante en la última convocatoria de las Cortes en Valencia en 1645, que realizó un análisis de las sentencias promulgadas en esta ocasión ${ }^{3}$.

Además de estas obras clásicas debemos tener en cuenta las crónicas en las que encontramos (aunque no siempre) breves menciones a algunas convocatorias de Cortes, como el caso de los Anales de Zurita ${ }^{4}$ y la crónica de Escolano y Perales. ${ }^{5}$

Muy importante en el estudio de las Cortes son las compilaciones de los fueros y privilegios realizadas ya desde el siglo XV hasta nuestros días, reunidos en base a un criterio cronológico o sistemático. La primera de ellas fue impresa por Lambert Palmart ${ }^{6}$ en 1482, en base a una copia de Gabriel Lluís d'Arinyó, que alcanza hasta

1. Belluga, P., Speculum Principium, París, 1530.

2. Mateu y Sanz, L., Tractatus de regimine urbis regni Valentiae, Valencia, 1654-1656.

3. Crespí de Valldaura, C., Observationes illustratae decissionibus Sacri Supremi Regii Aragonum Consilii, Supremi Sanctae et Regiae Audientiae Valentinae, Lyon, 1662.

4. ZuRITA, J., Anales de la Corona de Aragón, edición preparada por Angel Canellas López, Zaragoza,1969-1986, 9 vol.

5. Escolano, G., y Perales, J. B., Décadas de la historia de la insigne y coronada ciudad y reino de Valencia, Valencia, 1878-1880, edición facsímil, Valencia, 1980, 3 vols.

6. Furs e Ordinacions fetes per los gloriosos reys de Arago als regnícols el regne de Valencia, por Lambert Palmart, Valencia, 1482. Ed. facsímil por la Universidad de Valencia, Valencia, 1977, y por Vicent García, editores, Valencia, 1992. 
1446. Luego se editarían colecciones parciales de las leyes emitidas en determinados procesos correspondientes a fines del siglo XV y la primera década del siglo XVI. La segunda compilación legislativa fue realizada por Juan Mey en 15471548, sobre una copia del notario Francesc Joan Pastor, corregida por el abogado Juan de Capdevila, que comprendía las leyes promulgadas en las Cortes hasta 1542, siguiendo un criterio sistemático, es decir, siguiendo los títulos y las rúbricas de la legislación primitiva. Más tarde el mismo Juan Mey continuaría editando otros procesos como el de 1547, 1552, 1565, 1588 y 1604, y así sucesivamente hasta publicar la última convocatoria de Cortes en el reino de Valencia en 1645, edición que no vería la luz hasta 19847 .

La idea de una recopilación de todo el derecho valenciano sería recogida en las obras de Taraçona ${ }^{8}$ y Bartolomé Ginart ${ }^{9}$ o la recopilación de los privilegios llevada a cabo por Luís Alanya desde 1236 hasta 1513, incluyendo los de la capital del reino ${ }^{10}$.

El siglo de las Luces destaca por la total ausencia de ningún trabajo sobre la institución más representativa del reino de Valencia, tras la inminente implantación de la dinastía borbónica, símbolo de la centralización del poder, demostrado a través de la abolición de los Fueros.

Ya en el XIX, la exaltación del pasado medieval de los antiguos reinos de la Corona aragonesa, cuyos derechos y leyes se habían perdido con el absolutismo de los Borbones, se tradujo en numerosas publicaciones de los Furs, entre las que destacan, por citar solo algunas, las de Ribelles ${ }^{11}$, Capmany ${ }^{12}$, Boix ${ }^{13}$, Marichalar y Manrique ${ }^{14}$ o Danvila Collado ${ }^{15}$.

7. Guía Marín, L., «Cortes del reinado de Felipe IV», en Cortes Valencianas de 1645, Valencia, 1984.

8. Taraçona, J., Institucions dels Furs y privilegios del regne de Valencia e summari e repertori de aquells, Valencia, 1580

9. Bartolomé Ginart, O., Repertorio general y breu sumari per ordre alphabetic de totes les materies dels Furs de Valencia, fins les Corts del any 1604, y dels privilegis de la dita ciutat y regne, Valencia, 1608.

10. Aureum Opus regalium privilegiorum civitatis et Regni Valentiae, Valencia, 1515, por Luís Alanya, facsímil en 1972.

11. Ribelles, B., Memorias Histórico-críticas de las antiguas Cortes del Reino de Valencia, 1810.

12. Capmany, A., Práctica y estilo de celebrar cortes en el reino de Aragón, principado de Cataluña y reino de Valencia, y una noticia de las de Castilla y Navarra, Madrid, 1821.

13. Borx, V., Apuntes históricos sobre los Fueros del antiguo Reino de Valencia, Imprenta de D. Marinao de Cabrerizo, Valencia, 1855.

14. Marichalar, A., Manrique, C., Historia de la legislación y recitaciones del derecho civil de España, Madrid, 1863-1865.

15. Danvila Collado, M., Estudios criticos acerca de los orígenes y vicisitudes de la legislación escrita del antiguo reino de Valencia, Madrid, 1905; Estudios e investigaciones histórico-críticas acerca de las Cortes y Parlamentos del Antiguo Reino de Valencia, Madrid, 1906. 
Durante la primera mitad del siglo xx se realizaron interesantes investigaciones como la de Roque Chabás ${ }^{16}$ y Gual Camarena ${ }^{17}$, también acerca del derecho foral, o la obra de Martínez Aloy ${ }^{18}$ sobre la Diputación del General, institución nacida en el seno de las Cortes y que se convertirá en referencia para la historia del reino, incluso en nuestros días.

Respecto a los estudios mas recientes destacaremos a Silvia Romeu Alfaro, fundamentalmente su Catálogo y su más completa obra, Les Corts Valencianes ${ }^{19}$, de consulta indispensable para un conocimiento profundo sobre las Cortes, recogiendo una amplísima bibliografía. La obra divulgativa de Simó Santonja ${ }^{20}$ y la de P. López Elum donde combina el estudio acerca de los orígenes de los Fueros, con las convocatorias de esta asamblea a lo largo del siglo $\mathrm{XIII}^{21}$, careciendo por tanto de trabajos acerca de las convocatorias celebradas en el siglo XIV, centuria en que tienen lugar las Cortes objeto del presente estudio.

No debemos olvidarnos por otro lado, de otros trabajos sobre aspectos o instituciones relacionadas con las Cortes, realizados por Remedios Ferrero Micó, quien analiza en profundidad los agravios presentados por los brazos en las asambleas ${ }^{22}$, procedimiento propio de los reinos aragoneses, la Diputación o Generalidad valenciana, sobre la que han trabajado María Rosa Muñoz Pomer²3

16. Chabas, R., Génesis del Derecho foral valenciano, Imprenta de Francisco Vives Mora, Valencia, 1902.

17. Gual Camarena, M., «Contribución al estudio de la territorialidad de los Fueros de Valencia», en Estudios de la Corona de Aragón, III (1947-1948), pp. 262-289.

18. Martínez Aloy, J., La Diputación de la Generalitat del Reino de Valencia, Valencia, 1930.

19. Romeu Alfaro, S., op. cit.

20. Simo Santonja, L.V., Les Corts valencianes, 1240-1628, Valencia, 1997.

21. Lopez Elum, P. (ed.), Los orígenes de los Furs de Valencia y de las Cortes en el siglo XIII, Biblioteca Valenciana, 2001.

22. Ferrero Mico, R., «Mecanismos de control legal en el derecho valenciano», en Homenaje al profesor García Gallo, 1991, pp. 105-120; "Greuges y contrafueros en el derecho valenciano», en Dels Furs a l'Estatut. Actes del I Congrés d'Administració Valenciana: de la Historia a la Modernitat, Valencia, 1992. pp. 285-292; «Los greuges en las Cortes valencianas de 1510», en XV Congreso de Historia de la Corona de Aragón: el poder real en la Corona de Aragón (ss. XIV-XV), Jaca, 1993, pp. 193-205.

23. Muñoz Pomer, M $M^{a}$ R., «Las Cortes de 1339 paso previo en la alianza peninsular contra los benimerines», en Estudios dedicados a J. Peset Aleixandre, Universidad de Valencia, 1982; idem «La Generalidad valenciana vista por dietaristas y cronistas», en Anales de la Universidad de Alicante. Historia Medieval, 2 (1983), pp. 93-118; idem «Bases municipales de un impuesto general: las Cortes de Valencia de 1329», en Saitabi, XXXIII (1983), pp. 85-96; «Las Cortes de Cullera-Valencia de 1364», Saitabi, XXXV (1985), pp. 87-94; «Las Cortes de Valencia en 1358», en Saitabi, XXXVI (1986), pp. 155-166; Orígenes de la Generalidad valenciana, Valencia, 1987; en «Las Cortes valencianas de los siglos XIII al XV», en La Corona de Aragón. Cortes y Parlamentos, Zaragoza, 1988, pp. 206-257; idem «Cortes y parlamento de 1360. Acuerdos y distribución de donativos», en Estudios en recuerdo de Silvia Romeu Alfaro, vol. II (1989), Valencia, pp. 643-657; idem «Les Corts valencianes a 1'Edat Mitjana», Saó, 1989, pp. 15-21; «Las Cortes valencianas de su origen a su consolidación (siglo XIII-XV)», en Aragón. Historia y Cortes de un reino, Zaragoza, Cortes de Aragón, 1991, pp. 121-124; idem «Las Cortes valencianas y el cambio de estructuras fiscales 
o Martínez Aloy ${ }^{24}$.

Con todo, el periodo menos conocido acerca del desarrollo de las Cortes lo encontramos en el Medievo, sobre todo el siglo XIV, un vacío que comenzamos a llenar ya hace unos años ${ }^{25}$, y del que presentamos una parte del trabajo realizado sobre la convocatoria celebrada en San Mateo y Valencia durante 1369.

\section{LAS CORTES DURANTE EL REINADO DEL CEREMONIOSO}

El número de reuniones de Cortes a lo largo de toda su existencia es un aspecto sobre el que no existe un acuerdo unánime, pero quizá el catálogo más fiable, sobre estas reuniones sea el realizado en su día por Silvia Romeu ${ }^{26}$.

Así, a lo largo de la centuria donde tuvieron lugar las Cortes que centran este artículo, el siglo XIV, se celebraron un total de dieciocho convocatorias. Dentro de las celebradas durante el reinado de Pedro IV - concretamente se reunieron en quince ocasiones, además de nueve Parlamentos- podemos observar una evolución de las Cortes, estableciendo cuatro etapas siguiendo el citado Catálogo de S. Romeu ${ }^{27}$ :

- De 1336 a 1356, etapa de fortalecimiento del poder, destacando sobre todo la derrota de la Unión en Épila y Mislata, enmarcadas dentro de las Cortes de 1349.

- De 1356 a 1364, período marcado por la guerra contra Castilla y las continuas peticiones económicas destinadas a financiar este enfrentamiento.

- De 1364 a 1378, momento caracterizado por la guerra en la isla de Cerdeña tras el levantamiento del juez de Arborea, momento en el que la Diputación pasa a ser una institución de carácter permanente.

- De 1376 a 1386, final del reinado del Ceremonioso y cuyas últimas Cortes celebradas en 1382-1384 se prolongaron hasta la misma muerte del monarca en 1387.

Pedro IV inauguró su reinado en 1336 con sus primeras Cortes, las cuales destacaron por el proceso llevado a cabo contra Leonor de Castilla, madrastra del rey, y sus hermanastros los infantes Fernando y Juan.

en el tránsito del siglo XIV al XV», en Anuario de Estudios Medievales, (1992), pp. 463-483; idem «Las Cortes valencianas y su participación en las empresas italianas», en XIV Congresso di Storia della Corona d'Aragona, Sassar, 1996, pp. 615-628; «Problemas de Historia del Parlamentarismo: las Cortes valencianas», en Archivo Sardo, 47/49 (1996), pp. 219-235.

24. Martínez Aloy, J. Op. cit..

25. El presente artículo es un extracto de unos de los tres procesos estudiados en la Memoria de Licenciatura presentada en el año 2000, en la cual se analizaban, además de este proceso de 1369, también el de Valencia de 1371 y las Cortes generales de Monzón de 1375.

26. Romeu Alfaro, S., Op. Cit.

27. Idem, pp. 599-600. 
En la década siguiente, las Cortes se reunieron en tres ocasiones: 1342-1343, 1346 y 1349, destacando sobre todo éstas últimas ya que se anuló el privilegio de la Unión de Valencia, cuyo acto simbólico de ruptura del pergamino dio uno de los sobrenombres al propio monarca, conocido como En Pere del Punyalet.

Luego, en 1354, las Cortes se reunieron para cumplir con una de sus funciones más claras y definidas, recibir el juramento del primogénito real, en este caso el infante Juan, como heredero y sucesor de la Corona.

Ya a partir de 1357-1358, el motivo común de todas las convocatorias de Cortes fue la obtención de recursos económicos por parte de la Corona para financiar la guerra contra Castilla (1356-1366), creciendo notablemente el número de reuniones a partir de la década de los sesenta, como lo demuestran las Cortes de 1357-1358 (Valencia), 1360 (Valencia), 1362-1363 (Cortes generales de Monzón), 1364 (Valencia), 1365 (Sagunto) y 1367 (Castellón de Burriana) ${ }^{28}$, casi la mitad de todas las que convocó Pedro IV a lo largo de su extenso reinado. Igualmente la necesidad de obtener recursos, una vez concluida la guerra con Castilla en tierras valencianas, en este caso para hacer frente a la insurrección de la isla de Cerdeña o la amenaza de invasión del duque de Anjou sobre Mallorca, Rosellón y Cerdaña, fueron la causa principal de las convocatorias de 1369$1370,1371,1373-1374,1375-1376$ y $1382-1384^{29}$.

\section{LAS CORTES DE SAN MATEO-VALENCIA DE 1369-1370}

No conocemos el documento de la convocatoria de estas Cortes, ni la fecha de su inicio, si bien en base a la documentación estudiada debieron comenzar durante el primer semestre de $1369^{30}$, aspecto señalado igualmente por Zurita. ${ }^{31}$ Por su parte, $M^{a}$ Rosa Muñoz Pomer, en su estudio sobre la Generalidad, afirma que esta reunión fue convocada para el 28 de abril de ese mismo año, teniendo lugar el discurso real el 7 de mayo ${ }^{32}$. No obstante, la inauguración tuvo lugar en la villa de San Mateo, desde donde se trasladaron a la capital del reino para ser clausuradas el 20 de febrero de 1370.

Dicho proceso se inició directamente con el ofrecimiento por parte de los tres brazos, el militar, el eclesiástico y el real, de un servicio o donativo econó-

28. Romeu Alfaro, S., «Catálogo de Cortes...», p. 593.

29. Muñoz Pomer, $M^{\mathrm{a}} \mathrm{R}$., «Las Cortes valencinas y el cambio de estructuras fiscales...».

30. A.C.A., leg. 1507 , ff. 95 v. -118 r.

31. Zurita relata que el monarca se encontraba en Valencia en el mes de junio de 1369 y el parlamento ya había comenzado su desarrollo. Zurita, J., Anales de la Corona de Aragón, ed. Ángel Canellas López, Zaragoza, 1969-1986, t. 4, 1. X, cap. VII, p. 595.

32. Muñoz Pomer, Ma R., Orígenes de la Generalidad Valenciana, Generalidad Valenciana. Conselleria de Cultura, Educación y Ciencia, Valencia, 1997, p. 97. 
mico al monarca Pedro IV, motivo o causa de esta reunión de los representantes del reino valenciano:

«attenents la necessitat esdevenidora per vós, senyor, affermada e a ells e explicada en la dita Cort, que:s pot e s'espera advenir en el dit regne per guerra de Castella, esdevenidora e començadora» ${ }^{33}$.

La necesidad económica fue la causa de convocatoria que reunió a las Cortes prácticamente desde el inicio del reinado de Pedro IV, como ya hemos adelantado. Es el caso de los procesos de Valencia (1357-1358 y 1360), Cortes generales de Monzón (1362-1363), Valencia (1364), Sagunto (1365) y Castellón de Burriana (1367), ya que la guerra no finalizaría hasta la muerte del Cruel en 1369, momento en que la contienda se trasladaría al territorio vecino ${ }^{34}$.

Los asistentes a esta reunión podemos conocerlos a partir de las firmas en las actas resultantes del proceso de los síndicos o procuradores, sobre todo en el caso de las ciudades y villas reales, y fueron los siguientes:

\begin{tabular}{|l|l|}
\hline \multicolumn{2}{|l|}{ BRAZO ECLESIÁSTICO } \\
\hline Ombert de Tous (Montesa) & Guerau de Montbriu (Culla) \\
\hline Ferran Jirones (San Mateo) & Guillem Dende (Quart) \\
\hline BRAZO MILITAR & Berenguer Mercader \\
\hline Pere de Centelles & Joan Ximenis de Montetornés \\
\hline Ximén Pere d'Arenós & Dalmau Jàfer \\
\hline Roderic Sanví de Calatayud & Guillem Mir \\
\hline Pasqual Maçana & Miquel Palomar \\
\hline Francesc del Bosch & \multicolumn{2}{|l|}{} \\
\hline BRAZO REAL & Pere Doménech (Morella) \\
\hline Ramón Tolsà (Valencia)
\end{tabular}

33. Actas de Cortes de San Mateo-Valencia, A.C.A., leg. 1507, f. 96 r.

34. Romeu Alfaro, S., «Catálogo de Cortes valencianas hasta 1410», en A.H.D.E., XL (1970), Madrid, p. 593. Para mejor conocimiento de la contienda en tierras valencianas señalamos los siguientes estudios: CABEzuelo Pliego, J. V., La guerra de los dos Pedros en tierras alicantinas, Instituto de Cultura Juan Gil-Albert, Alicante, 1991; Camarena Mahiques, J., «La política peninsular de Pedro el Ceremonioso», en VIII Congreso de Historia de la Corona de Aragón, II, Vol. III, Valencia, 1973, pp. 9-30; Ferrer i Mallol, Ma T., «Causes y antecedents de la guerra dels dos Peres», en Boletín de la Sociedad Castellonense de Cultura, LXIII (1987), Castellón, pp. 445-508. «La frontera meridional valenciana durant la guerra amb Castella dita dels dos Peres», en Pere el Ceremoniós i la seva època, Institució Milà i Fontanals (C.S.I.C.), Barcelona, 1989, pp. 245-357; MuÑoz Pomer, M M $^{\mathrm{a}}$., «Preliminares de la guerra de los dos Pedros en el reino de Valencia (1356)», en Anales de la Universidad de Alicante. Historia Medieval, 1 (1982), Alicante, pp. 117-134. 


\begin{tabular}{|l|l|}
\hline \multicolumn{2}{|l|}{ BRAZO REAL } \\
\hline Pere Moster (Castelló) & Guillem Ripoll $^{35}$ \\
\hline Francesc Ballester (Burriana) & Joan Pineda (Vila-Real) \\
\hline Francesc d'Oriola & Vital Gomeç (Alicante) \\
\hline
\end{tabular}

A través de este compartiment conocemos las ciudades participantes en esta asamblea y en consecuencia, observamos la asistencia de localidades habituales en las Cortes de todo el siglo XIV, como Valencia, Xàtiva, Alzira, Burriana, Alpuente y Castielfabib. El resto aparecen en mayor o menor medida a lo largo de esta centuria, como el caso de Orihuela, presente en las Cortes de 1329 y 1367 , Guardamar (1329), Alicante (1329 y 1367) y Jijona en $1360^{36}$.

Los testigos del proceso fueron Pere Galcerà de Pinós, Ferran López de Heredia, Francesc Ça Gàrriga -alguacil-, Joan de Montboy, Guerau de Palou -promotor real y secretario-, Bertrán Dez Vall - consejero del rey- y Bernat de Bonastre, secretario real y notario de estas Cortes. Por el contrario, no se menciona a los tratadores del proceso, encargados de llevar a cabo las negociaciones.

Ya hemos señalado que el motivo de esta reunión fue de índole económico, cuyo objeto era subsanar los gastos derivados de la guerra contra Castilla iniciada en 1356 y que por estas fechas, ya se había trasladado a tierras castellanas, tras la muerte de Pedro I, el Cruel, en marzo de 1369. Por ello, las Cortes concedieron un donativo consistente en el préstamo de «doents hòmens a cavall, ço és, los cent armats e los cent alforrats, e cent lances a temps d'I any» ${ }^{37}$, cuya soldada, a cargo de la Diputación, se fijaba en siete sueldos diarios para los jinetes de caballería pesada y cinco para los de la ligera, mientras el lancero cobraría ocho sueldos. En total, el mantenimiento de las tropas ascendería a 40.000 libras, de las cuales 12.000 libras serían recaudadas a través de las generalidades, aplicadas por primera vez en 1329, y las 28.000 restantes mediante reparto entre los brazos o también llamado compartiment, combinando ambos tipos de impuestos. En el caso de no completarse el número de soldados contratados, el dinero sobrante se destinaría a sufragar 24.000 libras asignadas al conde de Denia en las Cortes de Monzón de 1362-1363 ${ }^{38}$.

35. Las actas no señalan la localidad a la cual representaba Guillem Ripoll.

36. Romeu Alfaro, S., Les Corts Valencianes, Valencia, 1985, pág. 64.

37. A.C.A., leg. 1507 , f. 96 r.

38. En esta convocatoria de Cortes la oferta ascendía a 250.000 libras para toda la Corona, de las cuales el reino de Valencia debía pagar 53.000 y que al parecer, todavía no se habían abonado, haciéndose numerosas referencias posteriores a este efecto. 
Además, $\mathrm{M}^{\mathrm{a}}$ Rosa Muñoz Pomer ${ }^{39}$ afirma que en estas mismas Cortes hubo un ofrecimiento de 18.950 libras, concedidas de modo urgente para la guerra de Cerdeña, surgida con motivo de la rebelión del juez de Arborea, cantidad abonada mediante reparto entre los tres brazos.

Las generalidades recayeron sobre toda la población ${ }^{40}$ y gravaban productos de primera necesidad, sobre todo alimentos como higos, pasas y miel (12 dineros/libra) o aceite ( 2 dineros/libra), u otros productos como grasa, pez, alquitrán y jabón (12 dineros/libra). Y tejidos como lana, estambre, lino, añino y estopa -a excepción de los destinados a los pobres o a ornamentos de iglesias- por los que se debía abonar 12 dineros por libra, así como la exportación de éstos (2 sueldos por libra), la exportación de cuero, así como las telas de oro y seda (12 dineros/ libra).

La distribución de las 28.000 libras acordadas se realizó del siguiente modo: 9.260 libras para el brazo militar, 4.985 para el eclesiástico y 13.750 para el real, cantidades que serían abonadas cada dos meses. No conocemos la distribución concertada para el brazo real, aunque sí en el caso de las Cortes de $1358^{41}$ y el parlamento de $1360^{42}$. En esta convocatoria de 1369-1370 aparece mencionada Bonaventura d'Arborea, esposa del señor de Jérica, única mujer convocada a estas Cortes, quien debía abonar 3.500 florines, incluidos los gastos derivados de los ataques que tuvieron lugar a lo mudéjares de Chelva, a los que debían contribuir además todos los vasallos musulmanes de esta comarca, aunque permaneciesen huidos, los cuales tenían la posibilidad de regresar a su lugar de origen, absueltos de toda pena, antes del plazo de tres años ${ }^{43}$.

Los acontecimientos ocurridos en Chelva durante la guerra de los «Dos Pedros», concretamente en este mismo año de 1369, tuvieron como víctimas a los mudéjares de esta comarca, que fueron atacados por sus vecinos cristianos por su falta de fidelidad al monarca aragonés. Junto a éstos, fueron atacados y robados

39. MuÑoz Pomer, Ma R., «Las Cortes valencianas y el cambio de estructuras fiscales en el tránsito del siglo XIV al XV», en Anuario de Estudios Medievales, 22 (1992), pp. 463-483; Orígenes de la Generalidad..., pp. 97 y 103.

40. «fo posada e ordenada generalitat en totes e sengles ciutats, castells, lochs, alqueries, poblats del dit rey, $e$ [...] totes persones, axí clergues, religioses, cavallers e persones generoses, com ciutadans, hòmens de viles, e de castells e alqueries, axi christians, com moros e juheus, e totes altres privades o estranyes de qualsevol estment, dignitat, e condició e manera». A.C.A., C. reg. 1507, f. 07 r.

41. Muñoz Pomer, Ma R., «La oferta de las Cortes de Valencia de 1358», en Saitabi, XXXVI (1986), pp. 155166.

42. Idem, «Cortes y parlamento de 1360. Acuerdos y distritución de donativos», en Estudios en recuerdo de Silvia Romeu Alfaro, vol. II (1989), Valencia, pp. 643-657.

43. Estos gastos ascendían a 700 florines (A.C.A., leg. 918, f. 65 r.). 
sus bienes a los mudéjares de Chulilla, Andilla y Villar, algunos incluso hechos prisioneros y violadas las mujeres ${ }^{44}$.

En el brazo eclesiástico casi la totalidad del dinero recayó sobre el obispado de Valencia, el Castellán de Amposta, los monasterios de Valldigna, Arguines, Porta-Colei y Poblet, y las órdenes de Calatrava, Vélez ${ }^{45}$ y Santa María de Montserrat, que abonarían un total de 1.235 libras, administradas por Antoni d'Alpicat, archidiácono de Sagunto, y el abad del monasterio de Valldigna. Las 3.750 libras restantes serían pagadas entre el obispado de Tortosa, la orden de Montesa, el monasterio de Benifassà y la priora de Sijena.

En cuanto a la asignación a las ciudades y villas reales fue la siguiente:

\begin{tabular}{|l|l|}
\hline CIUDADES Y VILLAS & CANTIDAD \\
\hline Valencia & $6.9431 ., 15 \mathrm{~s}$. \\
\hline Xàtiva & $1.9391 ., 5 \mathrm{~s}$. \\
\hline Morella & 1.847 1., $4 \mathrm{~s}$. \\
\hline Alzira & $9331 ., 11 \mathrm{~s}$. \\
\hline Castellón & $5261 ., 13 \mathrm{~s}$. \\
\hline Vila-Real & $2581 ., 9 \mathrm{s.}, 3 \mathrm{~d}$. \\
\hline Burriana & $2151 ., 9 \mathrm{s.}, 3 \mathrm{~d}$. \\
\hline Orihuela y Guardamar & $3431 ., 15 \mathrm{~s}$. \\
\hline Alicante & $2401 ., 12 \mathrm{s.}, 6 \mathrm{~d}$. \\
\hline Jijona & $681 ., 15 \mathrm{~s}$. \\
\hline Ademúz & $2031 ., 2 \mathrm{s.}, 6 \mathrm{~d}$. \\
\hline Castielfabib & $1711 ., 17 \mathrm{s.}, 6 \mathrm{~d}$. \\
\hline Alpuente & $1371 ., 10 \mathrm{~s}$. \\
\hline
\end{tabular}

En esta parte de las actas referida al abono del donativo cabe señalar la referencia a los lugares despoblados del reino a causa de la guerra contra Castilla, calificados como tales por los diputados, exentos del pago y cuya diferencia se obtendría por vía de las generalidades.

La escasez de población, no solo de mudéjares, es una de las consecuencias de las continuas guerras en que se vio envuelta la corona aragonesa durante el reinado de el Ceremonioso (1336-1387), sobre todo la de los «Dos Pedros»

44. Ferrer i Mallol, Ma T., La frontera amb l'Islam en el segle XIV. Cristians $i$ sarraïns al País Valencia, Institució Milà i Fontanals, Consell Superior d'Investigacions Científiques, Barcelona, 1988, pp. 23-24.

45. Con este nombre aparece citada una de las órdenes militares que debía contribuir al abono del donativo, a pesar de que la desconozcamos. 
(1356-1369), a cuyos efectos directos (muertes, migraciones, destrucción de viviendas, cosechas...) podríamos añadir las malas cosechas y epidemias que azotaron la Península y el occidente europeo durante el siglo XIV, sobre todo la Peste Negra de 1348-1352, y los subsiguientes brotes epidémicos ${ }^{46}$. Los ejemplos más significativos de esta despoblación en el reino de Valencia fueron Alicante, el Valle de Elda y Orihuela, cuyas morerías desaparecieron por completo ${ }^{47}$.

La administración del donativo estuvo en manos de la Diputación formada por seis diputados - dos por cada brazo- retribuidos con 3.000 sueldos anuales, más 20 diarios en caso de abandonar la ciudad de Valencia por algún motivo relacionado con el cargo. Tales diputados fueron Pere Centelles y Ruy Sánchez Calatrava, por el brazo militar; Antoni d'Alpicat y Guillem d'Avinyó por el eclesiástico y Guillem Mir y Miquel de Palomar -también clavario del proceso- por el brazo real.

Los consellers encargados de rendir cuentas a los diputados fueron igualmente seis: Vidal de vilanova y Pasqual Maçana por el estamento militar; Ombert de Thous y Joan d'Espejo por el eclesiástico y Francesc del Bosch y Arnau de Morera por el real. Además de un escribano, Guillem Serrà, un portero, Jaume Çavila, contadores, abogados, asesores, colectores...

\subsection{Capitulos presentados por los tres brazos}

Los veintiún capítulos aprobados por estas Cortes de San Mateo-Valencia podemos enmarcarlos en cuatro grandes áreas temáticas: economía, sociedad, competencias jurisdiccionales de los oficiales de la administración real y capítulos judiciales y penales.

Dentro del área social destacan los capítulos sobre minorías étnico-religiosas que formaban parte de la sociedad valenciana y de toda la corona de Aragón, a saber, los mudéjares y los judíos.

En uno de los capítulos los brazos protestaban por la concesión masiva de licencias o guiatges por el monarca ya que «gran part dels dits moros s'ixen del dit regne e buyden la terra», ${ }^{48}$ provocando pérdidas de población sarracena, tanto

\footnotetext{
46. Los efectos provocados por esta epidemia sobre la capital del reino valenciano aparecen en la Crónica del Ceremonioso, Cf. Jaume I, Bernat Desclot, Ramon Muntaner, Pere III, Les quatre grans cròniques, cap. IV, 44 pág. 199. Vid. También Rubio Vela, A., Peste Negra, crisis y comportamiento social en la España del siglo XIV. La ciudad de Valencia (1348-1401), Universidad de Granada, 1979; Sobrequés Callicó, J., «La Peste Negra en la Península Ibérica», en Anuario de Estudios Medievales, 7 (1970-1971), pp. 67-102; Ubieto Arteta, A., «Cronología del desarrollo de la Peste Negra en la Península Ibérica», en Cuadernos de Historia, 5 (1975), pp. 47-66.
}

47. V.V.A.A., Historia de la Provincia de Alicante, vol. III, Ediciones Mediterráneo, S.A., 1991.

48. A.C.A., C. reg. 1507 , f. 108 v. 
en los señoríos como en las tierras de realengo, lo que repercutía gravemente en el sector agrícola, al que se dedicaban mayoritariamente, y en consecuencia, sobre las rentas señoriales.

El reino de Valencia se encontraba en un ambiente de crisis demográfica y la población mudéjar -y el resto de la población en general- venía descendiendo progresivamente desde comienzos del Trescientos, descenso especialmente significativo en tierras de realengo, ya que la situación era más favorable en algunas aljamas de señorío, como las de Elche y Crevillent, el valle del Vinalopó o el marquesado de Denia en la provincia alicantina.

La política regia para con los musulmanes varió a lo largo del siglo XIV en función de las presiones de la nobleza o de la guerra contra Castilla. En 1347, el Ceremonioso aprobó la total libertad de movimiento para los sarracenos valencianos, pero en las Cortes generales de Monzón de 1362, a petición del brazo real, prohibió la emigración, aunque poco después, tras la firma de la paz con Castilla -en julio de 1363- de nuevo se les permitiría viajar. En 1369, al reanudarse la contienda contra el reino castellano, el monarca restringiría de nuevo la concesión de licencias por un periodo de diez años.

Por el contrario los judíos, a pesar de haber sufrido igualmente las consecuencias de la crisis del siglo XIV y de la guerra de los «Dos Pedros», respondieron favorablemente a la política de atracción del Ceremonioso con la que se reactivaron de nuevo las juderías valencianas, dando lugar a un incremento de esta minoría, como muestra la petición realizada en estas mismas Cortes para que los hebreos de la ciudad de Valencia que hubiesen alquilado o comprado casas fuera de la judería vuelviesen al perímetro de la misma. El baile general sería el encargado del cumplimiento de lo acordado con el fin de «que tot escandol e tot peccat per la dita raó ces», ${ }^{49}$ por lo que la política de segregación de esta minoría en cuanto a la residencia en barrios específicos, las juderías, no se cumplía a rajatabla.

Por su puesto carecemos de fuentes documentales, pero este crecimiento demográfico de la población judía provocó que finalmente, en 1389, se les reconociera el ensanche de la judería, aunque la situación cambiaría radicalmente con los ataques perpetrados contra las juderías de toda la Península en 1391, que supondrían el principio del fin de esta comunidad. ${ }^{50}$

49. A.C.A., C. reg. 1507, f. 111.

50. Cfr. Hinojosa Montalvo, J., «La comunidad hebrea en Valencia: del esplendor a la nada (1377-1391), Saitabi, XXXI (1981), Universidad de Valencia, Valencia, pp. 1-26; Ídem, «Bosquejo histórico de los judíos en tierras alicantinas durante la Baja Edad Media», Actes $1^{e r}$ Col-loqui d'hitòria del jueus a la Corona d'Aragó, Lleida, 1991, pp. 207-220; Ídem, Los judios en tierras valencianas, Valencia, 1996; PiLEs Ros, L., «Los judíos valencianos y la autoridad real», en Sefarad, VII (1947), pp. 151-156, Ídem, y La judería 
Otro de los aspectos tratados en esta convocatoria de Cortes fueron las competencias y funciones de algunos de los oficiales públicos como el justicia o el mustaçaf. Sobre el primero de ellos se confirma que no está obligado a prestar la inquisición de mero oficio fuera de la ciudad, villa o lugar donde ejerciera su cargo, al igual que tampoco debía abonar el dret de capit, tasado en 60 sueldos.

Los brazos denuncian la intromisión del portantveus de governador en la jurisdicción del almotacén o mustaçaf, cuyos funciones variaban desde velar por la legalidad de los pesos y medidas, vigilar la limpieza de las calles, el mercado y los oficios artesanos y cuestiones relacionadas con la edificación ${ }^{51}$.

También, se prohíbe a los notarios y jueces que no residan en la ciudad o reino de Valencia el ejercicio de su cargo dentro de las fronteras del reino, bajo pena de cien morabatines.

El aspecto económico, junto a las cuestiones judiciales y penales, es el tema tratado con más profundidad en este proceso. Por ejemplo, la sal, producto de enorme importancia en la economía medieval para la alimentación y como fuente de ingresos para el fisco real a través de las gabelas ${ }^{52}$. Los brazos denuncian la venta de este producto por encima del precio establecido por los fueros (6 sueldos el cahíz), excepto para la gabela de Burriana, donde solía venderse por 4 sueldos. Además solicitan la concesión real de licencia para la importación de este preciado producto a mejor precio.

En el ámbito comercial estas Cortes denuncian la exportación de metales por parte del monarca y sus oficiales, quienes habían concedido licencias o permisos de extracción de plata y cobre, lo que repercutía negativamente en la economía valenciana, ya que las minas importantes escaseaban, aunque el rey niega la concesión de tales permisos, ratificando la pena establecida al efecto en diez morabatines.

Los censales debidos por algunos de la villa de Sagunto a los nuevos pobladores que habían recibido posesiones en dicha localidad, como casas y bienes

de Valencia: estudio histórico, Universidad de Barcelona, Barcelona, 1991; Roca Traver, F. A., Los judios valencianos en la Baja Edad Media, 1996.

51. Sevillano Colom, F., «De la institución del Mustaçaf de Barcelona, de Mallorca y de Valencia», en A.H.D.E., XXIII (1953), pp. 525-538; Valencia urbana medieval a través del oficio del Mustaçaf, Institución Alfons el Magnànim, Valencia, 1957; ChalmetA, P., «El gobierno del zoco en Al-Andalus». R.V. Complutense, XXI (1972), pp. 41-83; idem, El señor del zoco en España: edades media y moderna. Contribución al estudio de la historia del mercado, Madrid, 1973.

52. Cfr. Gual Camarena, M., «Para un mapa de la sal hispana en la Edad Media», en Homenaje a J. Vicens Vives, 1065, pp. 483-497; SÁnchez Adell, J., «Notas para la historia de la sal en la Edad Media Valenciana», Millars, II (1975), pp. 29-45; SALVAdor Esteban, E., «La comercialización de la sal en el reino de Valencia durante la época foral moderna», en Homenaje al Dr. Juan Peset Alexandre, Universidad de Valencia, 1982, t. III, pp. 517-540; Hinojosa Montalvo, J., «Las salinas del mediodía alicantino a fines de la Edad Media», en Investigación Geográfica, 11 (1993), Alicante, pp. 279-292. 
raíces cargadas con censos como la enfitéusis, la fadiga o el luismo, pero que no podían hacer efectivos por haber caído prisioneros o trasladados a Castilla con motivo de la guerra. Esta situación dio lugar al sobreseimiento de estas deudas gracias a un fuero aprobado en las Cortes de Cullera-Valencia $(1364)^{53}$, pero ahora de nuevo los brazos solicitaron la nulidad de los mismos.

Hay que tener en cuenta que la villa de Sagunto sufría una grave situación de despoblamiento tras la guerra de los «Dos Pedros», pues ya en 1364, Pedro IV daba licencia a cuantos vecinos de Orihuela acudiesen a poblar esta localidad, concediéndoles el derecho a ser elegidos, cada año, jurados municipales.

Por último, los capítulos judiciales y penales tratados en esta asamblea giraron entorno al crim de collera o delicte de plagi, castigado por los tribunales reales -el gobernador real, incluso en las baronías- con la pena capital para el delincuente y sus encubridores ${ }^{54}$, salvo que las pruebas no fuesen del todo claras o en el caso de los collerats cristianos, quienes solían obtener el indulto ${ }^{55}$. En general, las penas se hacían efectivas tras un interrogatorio sometido a torturas, por lo que los brazos solicitan copia de los procesos sobre este tipo de causas. El monarca establece que los acusados contarán con un plazo de 10 días para preparar su defensa.

En general, los acusados de cualquier delito serían conducidos a la prisión común y los juicios incoados por el Consell y la Procuración -después Gobernación General del reino- contra los habitantes del reino de Valencia debían celebrarse en el lugar de residencia del acusado.

Igualmente, las sentencias emitidas por la Gobernación a través de los asesores o lugartenientes del portantveus de gobernador, estarían exentas de tasas y salario alguno, bajo pena de 12 morabatines de oro «exceptades comissions de comptes, les quals puxen fer los dits officials a qui per bé tendran e que aquells a qui seran comanats puxen pendre salari» ${ }^{56}$.

Las inquisiciones de mero oficio, a petición del brazo real, quedarían sobreseídas hasta dos años y se aprueba la remisión de penas impuestas por todo tipo de crímenes y delitos, incluido el de hosts fallides, a excepción de «traydors,

53. No se conserva el proceso de estas Cortes. Cfr. Muñoz Pomer, Ma R., «Las Cortes de Cullera-Valencia de 1364», en Saitabi, XXXV (1985), pp. 87-94.

54. A.O., Pedro IV, priv. LXXVII, pp. 305-306.

55. Cfr. Ferrer i Mallol, Ma T., La frontera amb l'Islam en el segle XIV. Cristians i sarraïns al País Valencia, Barcelona, 1988, cap. 3; idem, Organització i defensa d'un territori fronterer: la governació d'Oriola en el segle XIV, Institució Milà i Fontanals (C.S.I.C.), Barcelona, 1990.

56. A.C.A., C. reg. 1507, ff. 110 v.-111 r. Se cumplía así con el fuero aprobado en 1342 y se convertía en perpetuo aprobado en 1362-1363: Furs e ordinacions..., Cortes de 1342, Rúbrica XIIII, pág. 242 y Cortes de 1362-1363, Rúbrica XLIIII, pág. 285. 
sodomites, fabricadors de falses monedes, trencadors de camins o si havian comès crim de lesa majestat» ${ }^{57}$.

Por último, los brazos solicitan que el monarca renuncie a la parte que recibía procedente de legados píos efectuados en el obispado de Valencia (1/3), puesto que dicha cantidad unida a la oferta económica de estas Cortes, constituía una presión fiscal demasiado elevada, ante lo que Pedro IV consideró esta petición, exigiendo el pago tan sólo de las cantidades que estuvieran pendientes de cobro.

\section{CONCLUSIÓN}

Las actas examinadas sobre el proceso de Cortes de San Mateo-Valencia de 1369 incluyen además de los capítulos del donativo y de los agravios comentados, varias sentencias. La primera de ellas, a petición del brazo militar y eclesiástico, trata del juramento de toma de posesión del justicia y jurados de la ciudad de Valencia, realizado tres días antes de la Natividad del Señor, y en el cual se otorgaran franquicias a los vecinos de la ciudad o residentes por un periodo de cinco años.

Un segunda sentencia, firmada el 25 de febrero de 1370, prohíbe el uso de los bovalares o zonas de pasto de los señoríos al ganado de la ciudad de Valencia, bajo pena de 5 sueldos, del mismo modo, que los jurados de la ciudad embargarán el ganado ajeno a la contribución de la capital.

Finalmente aparece una carta de Pedro IV, fechada en Tarragona el 1 de abril del mismo año, prohibiendo a los oficiales catalanes cualquier embargo contra deudores de los donativos concedidos en las pasadas Cortes generales de Monzón (1362-1363) y las particulares de Tortosa (1364-1365) y Barcelona (1368) ${ }^{58}$, otra prueba mas de la fuerte presión económica de la Corona sobre el reino. Con el fin de poder hacer frente a la política belicista de el Ceremonioso, el 7 de mayo el rey hace mención de nuevo al donativo concedido en las Cortes generales de Monzón de 1362-1363, ordenando al portero real, Pere Molins, que exija a los diputados del brazo militar del reino valenciano el pago de 11.403 sueldos y 5 dineros y óbolo de Barcelona, todavía sin abonar transcurridos seis años.

Con todo, estos fueron los agravios presentados por primera vez por los tres brazos miembros de las Cortes, los señores valencianos -laicos y eclesiásticosjunto al brazo de las ciudades y villas de realengo, ante Pedro IV, a cambio del

57. A.C.A., C. reg. 1507 , f. $111 \mathrm{v}$.

58. Los donativos ascendían a 250.000 libras, 120.000 1. y 150.000 1. respectivamente. Cfr. Cortes de los antiguos reinos de Aragón y de Valencia y Principado de Cataluña, Real Academia de la Historia, Madrid, 1896-1922, vols. III y IV. 
importante donativo, compuesto en esta ocasión por tropas para hacer frente preferentemente a la contienda que mantenía con el reino vecino de Castilla.

Estos capítulos fueron ratificados en San Mateo por el secretario real del proceso, Bernat de Bonastre, ante los testigos Guerau de Palou, promotor, Bertrán dez Vall, consejero real, y Pere de Vall, tesorero del rey, pasando a engrosar la legislación del reino de Valencia ${ }^{59}$.

Las Cortes de San Mateo-Valencia de 1369-1370 destacaron sobre todo por la unión de los brazos en sus solicitudes y agravios presentados al monarca, como forma de presionarle ante su inminente necesidad económica de la Corona, en un momento en el que el rey tenía dos frentes abiertos, Castilla y Cerdeña.

A las guerras protagonizadas por Pedro IV cabe añadir las graves dificultades sociales y económicas que atravesaba la Corona en el siglo XIV, epidemias y malas cosechas que se tradujeron en una elevada y continua presión fiscal, como lo demuestran las numerosas referencias a otras ofertas concedidas en otras Cortes sin cobrar aún.

Todo ello nos puede ayudar a conocer un poco mas cuál era la situación que vivía el reino de Valencia a través del organismo más representativo de la sociedad valenciana medieval. 